\title{
Neo-Schumpeterian simulation models
}

\author{
Citation for published version (APA):
}

Windrum, P. (2004). Neo-Schumpeterian simulation models. MERIT, Maastricht Economic Research Institute on Innovation and Technology. MERIT-Infonomics Research Memorandum Series No. 002 https://doi.org/10.26481/umamer.2004002

Document status and date:

Published: 01/01/2004

DOI:

10.26481/umamer.2004002

Document Version:

Publisher's PDF, also known as Version of record

\section{Please check the document version of this publication:}

- A submitted manuscript is the version of the article upon submission and before peer-review. There can be important differences between the submitted version and the official published version of record.

People interested in the research are advised to contact the author for the final version of the publication, or visit the DOI to the publisher's website.

- The final author version and the galley proof are versions of the publication after peer review.

- The final published version features the final layout of the paper including the volume, issue and page numbers.

Link to publication

\footnotetext{
General rights rights.

- You may freely distribute the URL identifying the publication in the public portal. please follow below link for the End User Agreement:

www.umlib.nl/taverne-license

Take down policy

If you believe that this document breaches copyright please contact us at:

repository@maastrichtuniversity.nl

providing details and we will investigate your claim.
}

Copyright and moral rights for the publications made accessible in the public portal are retained by the authors and/or other copyright owners and it is a condition of accessing publications that users recognise and abide by the legal requirements associated with these

- Users may download and print one copy of any publication from the public portal for the purpose of private study or research.

- You may not further distribute the material or use it for any profit-making activity or commercial gain

If the publication is distributed under the terms of Article $25 \mathrm{fa}$ of the Dutch Copyright Act, indicated by the "Taverne" license above, 


\section{MERIT-Infonomics Research Memorandum series}

Neo-Schumpeterian Simulation Models

Paul Windrum

2004-002

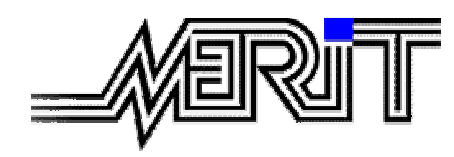

MERIT - Maastricht Economic Research

Institute on Innovation and Technology

PO Box 616

6200 MD Maastricht

The Netherlands

T: +31433883875

F: +31 433884905

http://www.merit.unimaas.nl

e-mail:secr-merit@merit.unimaas.nl

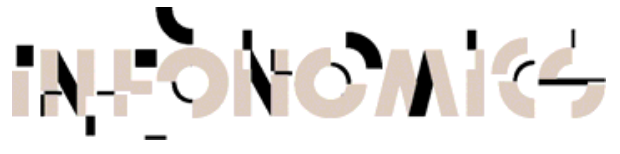

International Institute of Infonomics

c/o Maastricht University

PO Box 616

6200 MD Maastricht

The Netherlands

T: +31433883875

F: +31453884905

http://www.infonomics.nl e-mail: secr@infonomics.nl 


\title{
Neo-Schumpeterian Simulation Models
}

\section{Paul Windrum}

\author{
Manchester Metropolitan University Business School, UK*/ \\ MERIT, University of Maastricht, The Netherlands
}

\begin{abstract}
Forthcoming in The Elgar Companion to Neo-Schumpeterian Economics, edited by Horst Hanusch and Andreas Pyka
\end{abstract}

\begin{abstract}
The use of simulation modelling techniques by neo-Schumpeterian economists dates back to Nelson and Winter's 1982 book “An Evolutionary Theory of Economic Change”, and has rapidly expanded ever since. This paper considers the way in which successive generations of models have extended the boundaries of research (both with respect to the range of phenomena considered and the different dimensions of innovation that are considered), and while simultaneously introducing novel modelling techniques. At the same time, the paper will highlight the distinct set of features that have emerged in these neo-Schumpeterian models, and which set them apart from the models developed by other schools. In particular, they share a distinct view about the type of world in which real economic agents operate, and a invariably contain a generic set of algorithms. In addition to reviewing past models, the paper considers a number of pressing issues that remain unresolved and which modellers will need to address in future. Notable amongst these are the methodological relationship between empirical studies and simulation (e.g. 'history friendly modelling'), the development of common standards for sensitivity analysis, and the need to further extend the boundaries of research in order to consider important aspects of innovation and technical change.
\end{abstract}

JEL: C15, E17, L10,O30

Keywords: simulation modelling, innovation, structural change, industrial dynamics, economic development.

Correspondence address:

Manchester Metropolitan University Business School

Aytoun Street,

Manchester M1 3GH

E-mail: p.windrum@mmu.ac.uk 


\section{Introduction}

The use of simulation is now well-established within neo-Schumpeterian economics. Modellers have turned to simulation as a practical means of investigating complex models that are not tractable using traditional analytical techniques. The boom in simulation over the last twenty years means it is impossible to cover all the models that have been developed, or all the issues that have been raised by these models. The paper will therefore focus its discussion on a limited number of models. The models considered are the Nelson and Winter growth model, the Silverberg-Verspagen vintage capital model, the Dosi et al sector models, and the Windrum-Birchenhall and Malerba-Nelson-Orsenigo-Winter models. These have been selected according to two criteria: their influence in the field (e.g. a number of researchers have typically contributed to their subsequent development), and their ability to illustrate key research issues.

Sections 2 and 3 discuss the replicator algorithm and the distinguishing features of Type 1 and Type 2 simulation models. Sections 4, 5, and 6 discuss the modelling methods and content of the first generation of simulation models (Nelson and Winter, Silverberg-Verspagen, and Dosi et al, respectively). This enables us to identify the discernable set of features that set neo-Schumpeterian models apart from other (e.g. neo-classical) models, and which gives them a collective coherence. This coherence is shown to exist at two levels: the world in which real economic agents operate, and the set of algorithms that are used to model the behaviour of agents in this world. In particular, open-ended innovative search and selection form the dynamic cornerstone of neo-Schumpeterian simulation models.

Section 7 discusses the criticisms frequently levelled against the first generation of models, and the subsequent search for new methods of simulation testing and novel modelling techniques in order to address new research questions. This paves the way for a critical appraisal of recent models by Windrum-Birchenhall, and MalerbaNelson-Orsenigo-Winter. In Windrum-Birchenhall the elements of the neoSchumpeterian framework are radically stretched. By contrast, Malerba-NelsonOrsenigo-Winter marks a significant break from the neo-Schumpeterian. The paper evaluates both the contribution to methodology and modelling content. While attention has been placed on the contribution to methodology, this is shown to be a development of the original Nelson-Winter method. By contrast, the modelling content, though it has received relatively little attention, represents a radical departure because it seeks to dispense with open-ended innovative search and selection algorithms. 


\section{Replicator dynamics}

The selection algorithm is a distinguishing characteristic of the neo-Schumpeterian models discussed later in the paper. Of those used, the replicator algorithm has been particularly popular. Part of the replicator's attraction, no doubt, is its origin: the replicator was first developed by R.A. Fisher to model natural selection in biology (Fisher, 1930). Yet this is can only part of the explanation. Other selection algorithms, with equally strong evolutionary associations, exist. For instance, biased roulette wheels are widely used to model selection in genetic algorithms (GAs), and classifiers (see Goldberg, 1991; Holland et al., 1989). In addition to its origin, the replicator algorithm has a number of attractive qualities. First, it is simple to implement, and offers a practical solution to a particular problem. As such, it is a very useful tool in the simulator's toolkit. Second, the algorithm is well-established within economics, e.g. evolutionary games theory. Third, a set of tractable analytical results exist for the deterministic version of the replicator (see Fundenberg and Levine, 1998; Hofbauer and Sigmund, 1998; Samuelson, 1997; Weibull, 1995. The same cannot be said for GAs and classifiers, for example, where Holland's schema theorem of selection remains a subject of great controversy.

The deterministic version of the replicator contains a powerful theorem - Fisher's fundamental theorem of natural selection (also known as 'Fisher's Law'). This states that selection, given an initially complete set of $n$ objects (whether these be competing biological species or technologies) each with a differential level of fitness $f_{i}$, will work to reduce the number of competing objects until, in the limit, only that object with the highest relative fitness remains. A key driver of the process is a monotonic increase in the average fitness of the population $\bar{f}(x)$, which occurs as a result of objects with below average fitness being deleted from the population.

$$
\begin{array}{r}
\underset{1}{\&}=x_{i}\left[f_{i}(x)-\bar{f}(x)\right] \quad i=1, \ldots, n \\
\text { where } \bar{f}(x)=\sum_{i=1}^{n} x_{i} f_{i}(x)
\end{array}
$$

Translating Fisher's fundamental theorem into the economic domain suggests the market is a powerful selection mechanism that can evaluate the qualities of competing technologies and select that technology which is optimal for a given set of consumer preferences and production constraints. This has been investigated in formal models such as Soete and Turner (1984) and Metcalfe (1984). However, it was soon noted that Fisher's theorem is only valid for constant fitness functions and that very different outcomes can occur when selection is frequency-dependent, i.e. $f_{i}$ is not constant but depends on market/population shares (including its own share). These outcomes include the emergence of multiple equilibria and convergence solutions that are non-optimal. For example, in sequential selection models by Arthur, Ermoliev, and Kaniovski (1987), and David (1997) where the population of adopters increases 
over time, increasing returns to adoption and path dependence can result in the selection of sub-optimal technologies. Moreover, Banerjee (1992) has shown that, if decision-making is strictly sequential, then even improved information will not necessarily ensure convergence to a superior technology. Meanwhile, in models by Bruckner, Ebeling, Jiménez-Mantaño, and Scharnhorst (1994), and Weisbuch, Kirman, and Herreiner (2000) where the number of agents is constant in each period, frequency dependence can lead to convergence on a limiting distribution rather than a single state.

Two key modifications to the algorithm can be found in neo-Schumpeterian simulation models. The first is a consequence of an important shortcoming of the replicator: its blissful disregard of variety generation, whether through sexual reproduction in nature, or through human learning and innovation in economics. In terms of technical change, the relative fitness $f_{i}$ of competing technologies will change over time as a direct consequence of firms' innovative activities, although the payoffs associated with investments in innovation will be subject to a degree of random noise. Consequently, simulation modellers incorporate a stochastic version of equation (1) in their models.

A second modification involves adding a parameter to temper the strength of the replicator (e.g. in Metcalfe's (1984) analytic model, and Windrum and Birchenhall's (1998) simulation model). Again there are number of reasons for doing this. First, it is unlikely that markets are as efficient or as fast working as a replicator. In reality, consumers are constrained with respect to their ability to collect and process information on all available products, and product innovations, at each moment in time. Second, in circumstances where a technology space needs to be searched - i.e. the entire technology set is not initially present in the population - the probability of identifying a welfare enhancing technology is positively related to the number of firms searching that space. Given that consumers are boundedly rational, it makes sense to temper the strength of market selection. This distinction between those models assume a complete set of objects to be given and known at the outset, and those that do not, underpins the discussion in section 3.

\section{Type 1 and Type 2 simulation models}

Windrum's (1999) taxonomy distinguishes between two generic types of simulation model: 'Type 1' and 'Type 2' models. At a fundamental level, what distinguish them are two very different views about the world in which real economic agents operate. Everything in the Type 1 world can, in principle, be known and understood. Often it is assumed that the entire set of objects in the world (e.g. techniques of production, or products) is known at the outset. The opposite is the case in the Type 2 world. Here the set is unknown, and agents must engage in an open-ended search for new objects. Associated with this distinction are important differences with regards to the types of innovative learning and adaptation that are considered, definitions of bounded rationality, the treatment of heterogeneity amongst individual agents and the 
interaction between these individuals, and whether the economic system is characterised as being in equilibrium or far-from-equilibrium.

Neo-classical simulation models tend to be of Type 1, reflecting a primary interest in learning that leads to improvements in allocative efficiency. Two types of learning have been investigated in Type 1 models: inferential learning based on a Bayesian updating of decision rules where there is asymmetric or imperfect information, and action/strategy learning (notably in evolutionary games). In each case, learning is conducted within an equilibrium framework, the focus of the analysis being intertemporal coordination and, where the problem arises, ways of dealing with multiple equilibria. Risk is probabilistic in these models. Agents are boundedly rational to the extent that they have limited information, and collecting and processing new information is costly. However, it is assumed that all agents are endowed with appropriate algorithms to represent the environment. Hence they can, in principle, evaluate the outcomes associated with each alternative course of action. This in turn implies an assumption regarding interactions between agents. Representative agents predominate Type 1 models. When heterogeneity is incorporated, this is done in such a way that it does not disturb the equilibrium conditions.

A criticism frequently levelled by neo-Schumpeterians at Type 1 models is the narrow sense of innovation being explored. In contrast to Type 1 models, agents in Type 2 models engage in the open-ended search of dynamically changing environments. This is due to two factors. The first is the ongoing introduction of novelty and the generation of new patterns of behaviour, which are themselves a force for learning and adaptation. Agents operate in the presence of Knightian uncertainty: they cannot know ex ante the outcomes of a particular course of action (Knight, 1921). For example, firms must, through experience, improve their perceptions of the relationships between $R \& D$ investment and competitiveness, and to adjust their R\&D activities accordingly. However, the payoffs to R\&D are not static. On the one hand, each firm engages in $R \& D$ in order to improve its relative fitness - to change the payoffs in its favour. Yet, the final payoff cannot be known ex ante, because rival firms are also learning and innovating. The notion of bounded rationality is thus far broader than that considered in Type 1 models. Agents not only face problems with respect to their ability to collect and process information, they must also deal with the algorithmic complexity of the problem faced and their ability to define preferences over expected actions, events, and outcomes. In these models, agents are not initially endowed with an understanding of the underlying structure of the environment in which they operate but must develop a representation of the underlying structure. Further, radical innovation involves the introduction of new objects into the environment that alter this underlying structure and, hence, the payoffs associated with alternative actions.

The second factor underpinning open-ended search is the complexity of the interactions between heterogeneous agents. Interactions are non-linear are an important determinant of the final outcome of the system. Thus, in addition to specifying the dimension of heterogeneity amongst agents and the rules that govern their individual behaviour, one must specify the rules governing the interaction 
between agents. The macro phenomena that emerge will differ as a consequence of the interactions that occur between the individual members and subtle differences that exist within the heterogeneous population. If multi-scale effects exist, due to a further feedback between macro phenomena and individuals' behaviour, then small initial differences will be further magnified. Notable examples include differences in levels of R\&D expenditure between industries and Moore's Law in semiconductors. In the first case, it is suggested that differential levels of investment arise and persist because individual firms frame their expenditures with reference to average industry level expenditures (Silverberg, Dosi, Orsenigo, 1988). In the second case, it has been suggested a doubling of the processing capability of semiconductors every 1.5 years is maintained by the self-fulfilling expectations of firms in the industry (McKenzie, 1992; van Lente, 1993). Accepting Moore's law as a yardstick, and fearful that rivals will achieve this improvement, firms within the industry invest greater sums in R\&D to ensure the next generation of semi-conductors has twice the processing capability of the previous generation. Weisbuch, Kirman, and Herreiner (2000) observe that the presence of non-linearity and multi-scale effects such as these make it impossible to deduce macro behaviour from the behaviour of an 'average' or 'representative' individual.

The discussion highlights an important conceptual difference in the underlying nature of Type 1 and Type 2 models. As noted, Type 1 models view the underlying structure of the economic system as one of equilibrium. In Type 2 models, by contrast, the aggregate regularities that appear are not equilibrium properties but emergent properties that arise from the interaction between variety generation and selection. Indeed, the interplay between novelty generation and market selection drives the economic system 'far from equilibrium' and maintains it in a non-equilibrium state. Convergence tends to be transient rather durable. A shock to the system, e.g. a scientific discovery that prompts the development of a radical innovation, can lead to a fundamental change in the system's structure. Identifying the generic features of Type 2 models assists in focusing the discussion of the neo-Schumpeterian simulation models, their similarities and differences, strengths and weaknesses, in the remaining sections of the paper.

\section{Nelson and Winter growth model}

It is hard to overestimate the impact of the Nelson and Winter model on neoSchumpeterian economics. Its publication in 1982 stimulated a whole body of simulation research and its continuing legacy is evident two respects: first, the adoption of their approach to simulation modelling and, second, the diffusion of key elements of the model's content. A significant portion of the 1982 book is given over to the rationale for simulation and a discussion of how one should go about conducting simulation research. The authors' personal objective was to improve upon the traditional Solow one-sector growth model (Solow, 1957). To this end, they sought to develop a model whose explanatory content was greater than the Solow model, and which was more realistic in terms of its micro foundations of technical change and innovation. The latter led the authors to a consideration of the non-linear 
and highly stochastic interactions that occur between firms in the innovation process. Since these were not amenable to traditional analytical techniques, Nelson and Winter turned to simulation.

Having identified a need for simulation, Nelson and Winter considered how the modelling process should relate to ongoing empirical research, and introduced a twostep approach to the empirical validation of simulation models ${ }^{1}$. The first step involves the identification of the emergent properties - or 'stylised facts' as they called them - that the model is expected to replicate. Typically, these are industry or macro level phenomena ${ }^{2}$. Having passed this first step, the second step assesses whether the model can provide further insight into economic processes. In the case of their own model, it can account for the aggregate time paths for output (GDP), capital and labour inputs, and wages (labour share in output) observed in the first half of the $20^{\text {th }}$ century (step 1), and it establishes a link between firms' innovative performance and skewed distributions of firm size, diversity in market shares, and variability in firms market shares over time (step 2). Nelson and Winter's approach to simulation modelling has become the norm amongst neo-Schumpeterian simulation modellers.

In terms of content, the key elements of the Nelson and Winter model subsequently became a de facto standard for neo-Schumpeterian simulation models. These are: heterogeneity within a population of agents, a selection mechanism, and a novelty generation mechanism that maintains variety in the population over time. The firm is the basic unit of selection in the Nelson and Winter model. Heterogeneity in a population of firms is due to the differential productivity of the production techniques used to produce a homogeneous good. Each firm operates with just one production technique at a particular point in time, and consumer demand is assumed to be homogeneous in the model, such that demand curves are downward sloping and market price is exogenously given. Further, the homogeneous good assumption precludes improvement in relative performance through product innovation. Hence, market selection is driven by the relative efficiency of the alternative process technologies. While not explicit in this early model, a replicator dynamic is implicitly driving the selection dynamics over time. Firms using more efficient production techniques can offer lower priced versions of the standard product and their market shares will grow over time. By contrast, the market shares of inefficient, high-priced producers will decline over time and eventually die.

The third element of the model is the open-ended search for new, more efficient production techniques. Firms can improve their chances of success by substituting production techniques of below-average efficiency with techniques of above-average efficiency. The search process can take one of two forms: local search or imitation. In the first case, firms search for previously undiscovered techniques. A finite set of

\footnotetext{
${ }^{1}$ The procedure should not be confused with sensitivity analysis. This validatory procedure merely asks whether a model can generate an output that accords with an empirically observed phenomena. Sensitivity analysis considers the robustness of outputs by altering the values of key parameters and/or random inputs. At present there is not a generally agreed standard procedure for sensitivity analysis, either in the natural or social sciences.

${ }^{2}$ This is very different to Kaldor's (historically earlier) discussion of 'stylised facts' in modelling. Kaldor was referring to the use of empirical evidence to assist in the calibration of key parameter values (or ranges of values) in a model, not to the outputs generated by the model.
} 
alternative techniques exists but firms do not initially know what this set is. Further, firms are constrained in their search of this set. Translating the set into a search space of $n \times m$ dimensions, the probability of discovering a new technique declines linearly according to the technological distance (measured in Euclidean distance) from their existing production technique. This constraint is said to reflect limited current competencies or some other form of inertia. By varying the skewness of this distance function, a labour or capital bias can be introduced into the localised search process. Imitation, the second type of search process, involves a firm adopting a technique that is already employed by another firm. The diffusion process, though it does not involve the introduction of novelty within the population, will involve an upgrading of knowledge and skills by the imitating firm. It is assumed that the probability of imitating a particular technique is proportional to the current share in output of that technique. Finally, an additional source of innovation is the flow of new market entrants in the model. In this model, firms only engage in search if their rate of return falls below a given threshold (a parameter of the model). This is one of the most notable features of the model. According to Nelson and Winter, this captures the satisfysing behaviour of firms.

A number of subsequent authors have modified or extended the model. Yilizoglu (2001), for example, modifies the rules regarding investment in $R \& D$ and productive capital. In the original Nelson and Winter model, firms invest a fixed proportion of their profit in R\&D. Yilizoglu compares the performance of these 'NW firms' with 'Gen firms'. Gen firms adjust their R\&D expenditures by taking into account their own performance and those of rival firms. The learning procedure of these firms is modelled using a genetic algorithm (hence the name 'Gen'). Since both capital formation and future R\&D activity are financed from current profit, an additional decision rule needs to be added. Yilizoglu assumes R\&D investment takes priority, with capital investment equal to the remainder of profit after future $R \& D$ expenditure has been deducted. The simulation experiments that are conducted use different initial proportions of NW and Gen firms in the population. The findings indicate that Gen firms are more successful in identifying superior R\&D strategies, giving then a selective advantage. As a consequence, Gen firms tend to dominate the population over time. Further, the higher technological performance of Gen firms results in a higher level of social welfare.

Winter, Kaniovski and Dosi (2000) present a stripped down version of the Nelson and Winter model that explores the impact of new entrants on technological change. In part the aim is to generate a set of formal analytical properties of the model: three theorems and one lemma are analysed for the first version of the model and two theorems and one lemma for the second version. Simulation is used to explore a third version of the model that is not amenable to formal analytical techniques. In contrast to the original Nelson and Winter model, the model assumes that innovations are solely associated with new market entrants, i.e. incumbent firms do not innovate. Hence, variety is maintained by the random arrival of new firms with higher productive efficiency. In the first version of this model, differential competitiveness is determined by capital per unit of output. By contrast, in the second version of the model, differential competitiveness is determined by labour productivity (the 
capital/output ratio is assumed to be constant for all firms). In the third version, differential competitiveness depends on the efficient use of both factor inputs.

Kwasnicki and Kwasnicka (1992) have extended the Nelson and Winter model to consider multi-unit firms and (a degree of) product diversity. Specifically, the assumption of a homogeneous good is replaced by a set of alternative product variants. Production techniques remain the key driver of the model but now each technique determines the quality of the good as well as the underlying cost of production. Consumers are assumed to be homogeneous and so successful firms are those that identify techniques that offer attractive quality/price combinations for a given preference set. In contrast to Winter, Kaniovski and Dosi, only existing market incumbents introduce new product/process innovations. The key strategic innovation decision for these firms is whether to search for a more efficient production technique (embodied within a plant) or, alternatively to set up a new plant that produces a new product variant. Importantly, no knowledge constraints are placed on this latter process. This diverges from the behavioural assumptions of the original Nelson and Winter model, and is responsible for the phenomena of 'fitness jumping' - the distinguishing feature of the Kwasnicki-Kwasnicka model. The combination of radical product and radical process innovation, associated with the opening a new plant, is very powerful. Since firms in this model can instantaneously engage in any activity that improves their performance, they rapidly cluster around new production activities that are seen to be fitness enhancing. The identification a new, fitness enhancing activity is quickly transmitted and firms cluster around this new activity. The result is a rapid increase (jump) in the average fitness of the population.

\section{Silverberg-Verspagen vintage capital model}

It is interesting to note that, while a number of researchers subsequently extended the Nelson and Winter model, their interest was in applying the model to explain industry dynamics, not macroeconomic growth. Meanwhile, those modellers investigating macro dynamics tended to follow a different track. Though their models encompass the three key elements of heterogeneity, selection, and novelty generation, they typically eschew detailed firm-level descriptions in order to keep the complexity of the simulation model within manageable bounds (Verspagen, 1995). Of particular note a group that will be collectively labelled the ‘Silverberg-Verspagen' framework. The label indicates the important contributions of two of the key authors to this body of research, but the contributions of the other authors should not be overlooked. Key papers include Silverberg (1987), Silverberg, Dosi, and Orsenigo (1988), Silverberg and Lehnert (1993), Verspagen (1993) and Silverberg and Verspagen (1994).

A distinguishing feature of the Silverberg-Verspagen framework, is that technological progress is embedded in vintage capital. It is assumed that a single best practice technology exists at any one time, and that all current investments are made in this technology. Consequently, the capital stock in each period will comprise a set of vintages going back in time. The technological lifespan of capital equipment is 
defined by a specified scrapping margin that governs the oldest permissible vintage. This is related to technological obsolescence and/or wear and tear. The aggregate capital stock is then a sum or integral (in discrete or continuous time cases, respectively) over the vintages during this technological lifespan, and average technical coefficients - e.g. labour productivity and capital-output ratios - are the corresponding vintage-weighted sum or integrals.

A key advantage of the approach is that vintage capital stock is relatively easy to compute from empirical data. There are, however, two disadvantages. The first is the assumption of a singular 'best practice' technology in each time period. This is not supported by the empirical evidence, which indicates that alternative technologies may be competing at the technological frontier at any one time. To an extent Silverberg, Dosi, and Orsenigo (1988) overcame the problem by assuming a fixed set of vintage structures, of which multiple distinct technologies may coexist in the model. The second problem lies in the calculation of discrete-time vintage capital stocks. This can lead to awkward mathematical complications when they are embedded in a dynamic framework with endogenous scraping.

In each period, each firm has a variable number of different types of capital, and devotes resources to a search for new types of capital. Since all firms are assumed to produce a homogenous product, the problem is to determine how much to spend on this search activity, relative to current levels of profit and sales. The problem is complicated by the existence of increasing returns and technological spill-overs between firms. The first block of the framework describes the basis of selection. Silverberg (1987) and Verspagen (1993) use a replicator to model selection. In the later models, the various basic blocks are linked by a predator-prey master equation. However, the dynamics of the predator-prey and replicator algorithms are formally related $^{3}$. As in the Nelson and Winter model, selection is based on the differential productive efficiency of firms, but here relative efficiency is determined by the composite of vintage capital currently employed to produce a homogeneous good. Vintages of capital are distinguished by two technical coefficients: a capital coefficient $(c)$ and a labour coefficient $(a)$. For a given wage rate $(w)$, the profit rate for a particular vintage is (1-w/a)/c. While the capital coefficient is a constant, the labour coefficient and the wage rate change over time. Labour productivity is assumed to change under the influence of technical progress. In the long run, wages tend to track labour productivity through a Philips curve. Rising real wages provides an incentive fir firms to replace labour with capital. The current composition of capital can be upgraded by replacing older capital vintages with the latest vintage. This is funded by the profits generated by the current composite stock. Although the authors do not explore the link, this is reminiscent of Böhm-Bawerk's theory of interest and capital. In effect, old, less efficient capital is being transformed into newer, more efficient capital over time ${ }^{4}$.

\footnotetext{
${ }^{3}$ See Hofbauer and Sigmund (1998: 77-78) for a discussion of the formal relationship between the replicator dynamic and the Lotka-Volterra predator-prey equation.

${ }^{4}$ It would be interesting to consider the implications of technological change for Böhm-Bawerk's theory of interest.
} 
The second block of the model governs the introduction of new vintages of technology and new market entrants into the system. In this open-ended Type 2 model, new capital innovations are introduced in each period. Given the fixed labour productivities of each vintage, and ever-increasing real wages over time, each vintage of capital technology will at some point be superseded by newer technologies and become unprofitable. Note that, since it is assumed that losses are financed by running down capital stocks (scrapping), those firms operating with unprofitable capital vintages will tend decline over time. Firms are declared bankrupt, and exit the model, when their share of employment falls below a given threshold. As in the Nelson and Winter model, the number of firms operating in each period is constant with the exit of a given number of firms at the end of one period resulting in the creation of an equivalent number of new market entrants. These new market entrants are endowed with the latest vintage of capital.

The third block of the model governs the innovation process. As in the Nelson and Winter model, innovation is a search process comprising two parts: radical process innovation and imitation. While the imitation algorithm is very similar to that in the Nelson and Winter model, the algorithm modelling radical innovation differs significantly. The latter is governed by a Poisson process with a given arrival rate. The arrival rate depends on an 'innovation potential function' which has three determinants: the firm's current $R \& D$ funds, its distance from the best practice frontier, and the average $R \& D$ expenditure in the industry. These variables themselves evolve over time as a consequence of innovation and learning by the population of firms. The phenomena that have been addressed using the SilverbergVerspagen framework differ notably to those addressed by Nelson and Winter. Where the focus for Nelson and Winter was national (i.e. US) growth, contributors to the Silverberg-Verspagen framework tend to focus on technological interdependence and cross-national growth phenomena such as technology spill-over and technology catch-up dynamics.

\section{Dosi et al sector models}

The models developed by Dosi and collaborators in the early to mid 1990s sought to link differential growth rates of countries to variations in the pattern of innovation found in key economic sectors (Chiaromonte and Dosi, 1993; Dosi, Fabiani, Aversi, and Meacci, 1994; Dosi, Marsili, Orsenigo, and Salvatore, 1995). In these models, a firm is characterised by a single labour coefficient. Firms differ with respect to their technological capabilities (in the form of labour input coefficients), and their R\&D and price setting (mark-up) strategies. Unlike the Silverberg-Verspagen framework, however, these strategies do not evolve as a consequence of behavioural learning. Rather, firms' strategies are randomised at the outset and remain fixed over their lifetime.

The search space in Dosi-Fabiani-Aversi-Meacci is similar to the Nelson and Winter model. The probability of an innovation occurring is positively related to $R \& D$ 
investment (which is measured by the current and a lagged number of R\&D employees), with the improvement in productivity being randomly determined. By contrast, the search process in Chiaromonte and Dosi is a complicated twodimensional space of 'technological paradigms' and labour coefficients. Firms either produce capital goods (each of which is characterised by a set of coordinates in the two dimensional plane), or they produce a homogeneous consumption good (for which they need machines as inputs). Paradigms differ with respect to the labour coefficient required to produce a homogeneous consumption good. In the capital goods sector, the probability of identifying a new innovation is again positively related to the number of R\&D workers that are employed, and the productivity gain associated with a newly identified capital good is randomly determined in the model. In the consumption good sector, firms possess a skill level for each available type of capital good. This skill level evolves by a learning process that has private and public features. It is assumed that imitation is costless and instantaneous. Hence, when a firm improves its skill in using a particular capital good, this simultaneously improves the skills of all the firms that operate that particular capital good. Labour productivity depends on the characteristics of the capital good and the firm's skill level. Firms in the consumption good sector maximise a function involving labour productivity, prices, and an order backlog, and thereby choose which capital good they wish to use.

A replicator algorithm is used to model selection in each of the papers. In DosiFabiani-Aversi-Meacci, prices and exchange rates are the key variables that determine relative competitiveness. Thus the relative success of individual firms depends on labour productivity, wages and other aggregate characteristics, and behavioural variables (such as mark-up pricing rules). In Chiaromonte and Dosi, relative competitiveness also depends on back orders in the previous period. In all three models, firm exit the sector if its market share falls below a given critical level. The number of firms is constant over time. For each firm that enters the sector, a new firm is introduced. The initial productivity of the new entrant is set equal to the current average level of productivity in the sector and the country, plus a random white noise.

The discussion of generated model outputs is rather unsystematic in the Chiaromonte and Dosi, and Dosi-Fabiani-Aversi-Meacci. Clear-cut relationships between particular variables and outcomes are not established, and sensitivity analysis is not reported. Indeed, Chiaromonte and Dosi provide information on just one simulation run, and Dosi-Fabiani-Aversi-Meacci provide little information about alternative runs to those that are illustrated in the paper. These papers follow Nelson and Winter in placing an emphasis on empirical plausibility, based on the ability of the models to generate outputs that roughly accord with stylised empirical data (in this case for GDP exports and imports). The discussion in Dosi-Marsili-Orsenigo-Salvatore does go beyond the generation of stylised outputs (here s-curve diffusion patterns) to consider how alternative hypotheses about innovating firms (i.e. new market entrants, established firms or a combination thereof) and the kind of market selection can generate industrial structures with very different patterns of concentration, rates of entry and exit, stability/ turbulence, and distributions of firm size. However, this paper also does not provide information on rigorous sensitivity testing of these results. 


\section{Limitations of the first generation of models}

The first generation of simulation models (such as those discussed thus far) were an important component in the establishment of a viable, neo-Schumpeterian alternative to mainstream (neo-classical) economic thought. Indeed, the explicit objective of the early models was the demonstration of the feasibility of the new approach. In this respect the models were highly successful. They were capable of generating outputs that accorded with empirically observed phenomena while simultaneously providing evolutionary neo-Schumpetrian explanations for these phenomena. Still, there remained much scope for development and, by today's standards, the early models were limited in a number of respects. First, the empirical phenomena that were specified, and against which the model outputs were compared, were rather general and did not necessarily represent a difficult test. Second, a very limited range of agents were considered - in fact, just firms - and the representations of these agents were very stylised. Third, there was a noticeable lack of rigorous testing procedures. Rarely, for example, did authors engage in a sensitivity analysis of the model outputs.

A number of the limitations can be traced to weaknesses in Nelson and Winter's twostep validatory procedure of models assessment. As previously discussed, this involves an assessment of whether a model generates outputs that accord with one or more empirically observed phenomena. The procedure does not consider the nature of the selected empirical phenomena and whether these represent a sufficient test for the model, or how to go about comparing models that posit very different data generating processes. This parallels Brock's (1999) discussion of scaling laws in economics. Empirical regularities need to be handled with care because most of them are 'unconditional objects', i.e. they only indicate properties of stationary distributions and, hence, cannot provide information on the dynamics of the stochastic processes that generated them (Brock, 1999, p.410). Of the models discussed in this paper, the Silverberg-Verspagen and Dosi et al models differ significantly with respect to the behaviour and learning procedures of agents, and in their causal variables. Yet both produce similar outputs - outputs that mimic some very general empirical observations regarding differential growth rates between countries, and technology leadership and catch-up. Further, the Nelson and Winter model replicated highly aggregated data on time paths for output (GDP), capital and labour inputs, and wages (labour share in output) that could equally be replicated by conventional neoclassical growth models. A third criticism levelled at the early models was a lack of sensitivity analysis of the model outputs. As noted above, these often presented 'illustrative outputs' taken from a handful of simulation runs. Rarely did the authors conduct large numbers of simulation runs or systematically test the outputs for different parameter values or for different random seeds ${ }^{5}$. Rather, the papers tended to place emphasis on the interpretation of the outputs as empirically 'plausible'.

The content of the early models have also attracted criticism. As illustrated in sections 4, 5 and 6, firms were typically the only agents to be explicitly modelled.

\footnotetext{
${ }^{5}$ There were a few notable exceptions, such as Silverberg and Verspagen reviewed in this paper.
} 
Consumers and other agents were collectively shoehorned into an extremely opaque external 'selection environment' that was modelled via a replicator algorithm (or similar). Even the descriptions of firms' behaviour and learning procedures, and the interactions between firms, were very simple (and not that far removed from conventional neo-classical representations). Consequently, strong restrictions were imposed on the range of topics, and the types of research questions open to investigation. The role of consumers, government and other agents in the innovation process and, hence, their impact on technological change could not be addressed. Further, one could not investigate important areas of empirical research, such as product diversification, processes of vertical integration/disintegration (supply chains) and formal/informal horizontal alliances (innovation networks), services innovation, economic geography, and public sector innovation. There was a clear danger of imposing a highly conservative constraint on the continuing theoretical development within neo-Schumpetrian economics. Indeed, despite the avowed intention to break away from mainstream economic thought, the early models dealt with very conventional economic phenomena. In this respect, there is even a continuing and discernable imprint of neo-classical economics ${ }^{6}$. Subsequent researchers have sought to develop new research agendas and, as part of this process, have engaged in the development of models that are more amenable to these new research issues. Two examples of this second generation models are considered in the next section: the Windrum-Birchenhall model (1998, 2001), and the Malerba-Nelson-Orsenigo-Winter model (1999, 2001).

\section{Second generation simulation models: Windrum-Birchenhall, and Malerba-Nelson-Orsenigo-Winter models}

Windrum and Birchenhall (1998, 2001) present a multi-agent framework that that explicitly models consumers and firms. The nature and direction of technological innovation is determined by the interaction of heterogeneous consumer preferences and heterogeneous firm knowledge bases at the micro level. The emergent properties of the innovation process are, in turn, an important input in the learning processes of consumers and firms, leading to changing preferences and knowledge bases. The net result is the co-evolution of consumer preferences, firm knowledge bases, and technologies over time. The model is initialised with a given number of consumer groups, or 'classes', and a given number of firms (both are parameters of the model). Each consumer class is endowed with a single preference set. Each firm produces one product design, and each firm targets one particular consumer class. Firms are randomly assigned to consumer classes. Further, the initial characteristics of the design are randomised, as is the firm's initial mental model of the preferences of its target consumer class. The task facing the firm is to improve its mental model of the target preference set. This it achieves through product innovation and learning over

\footnotetext{
${ }^{6}$ Kuhn (1962) and Gribbin (1984) observe the same phenomena in physics at the turn of the last century. The pioneers who played a pivotal role establishing a new scientific paradigm were nevertheless trained in the old (classical) paradigm. This restricted the range of phenomena they considered, and they carried over concepts and theories from the old paradigm (many of which were subsequently rejected).
} 
time. Here firms not only take into account the consequences of their own past innovative activities but also the relative success/failure of their competitors' past innovative activities.

In contrast to the models previously discussed, innovation takes the form of product innovation. The authors observe that product quality is itself a complex concept. It is rare that a single product is unambiguously superior its rivals. Technically, different designs tend to excel in some aspects but are weaker in others. Further, the qualityprice trade-off varies between designs because higher quality designs are more expensive to produce. Additionally, quality is relevant to the current state of preferences (which themselves change over time). Different consumer classes of users attach different priorities (weights) to the various aspects. This variety reflects the different lifestyles, interests and values of the various consumer classes. For example, supermarkets today cater for distinct classes of shoppers: vegetarians, vegans, and those who wish to purchase organic produce. These classes of consumers did not exist, or else were very rare, twenty years ago, indicating that new classes can appear and disappear within a consumer population over time. In order to tackle the issue of product quality, the model adopts a Lancaster characteristics approach to products. Lancaster observed that products deliver a range of different services to the final user (Lancaster, 1971). In the model, a product is represented by a $1 \times X$ vector of characteristics, the value of each characteristic can range between 1 and 0 according to whether it is of higher or lower quality. Both the dimensions and the quality values can differ between rival technology products. The initial set of characteristic values are randomised in the model. Through innovation, firms are able to alter the values of the product characteristics they offer their target consumers.

The distinction between the population of consumers and consumer classes is an important aspect of the framework. A given number of individual consumers enter the market in each period. Each individual assigns him/herself to a particular consumer class. When an individual joins a group, (s)he adopts the preferences (i.e. the lifestyle and attitudes) of that class. In reality, the decision to join a particular group will itself be a complex phenomenon that involves a number of factors. One important factor is how well each class is currently being serviced by the technology products that are targeted at it. Consumers will converge to classes that are well serviced, and enjoy high levels of utility. By contrast, classes that are poorly serviced and suffer low levels of utility will tend to disappear over time. For each group that is eliminated from the model, a new class (with a new preference set) is introduced. This exit and entry of consumer classes is an important source of variety because it maintains a turnover of preferences for different bundles of characteristics over time.

The utility of each consumer class includes a quality component that takes the form of a $1 \mathrm{x} X$ vector of characteristics, with values ranging between 1 and 0 according to whether more or less of that characteristic is preferred, and a price space $P$ (positive real numbers). A replicator is used to model the selection process. In contrast to earlier models, selection in this framework operates on the relative success of alterative consumer-firm couplings, as measured by the relative utility associated with each consumer class. Over time, the share of classes with above above-average 
utilities grow and classes with below-average utility will decline. If there is just one firm servicing a particular time period, then its growth/decline directly corresponds to the growth/decline of its consumer class. If, however, more than one firm targets the same consumer class, then a firm's growth/decline additionally depends on the relative competitiveness of its products vis-à-vis rivals targeting the same consumer class.

Firm have strategies for mark-up pricing. The framework allows for these to strategies evolve as a consequence of behavioural learning (à la SilverbergVerspagen), else for mark-ups to be fixed over the lifetime of firms (à la Dosi et al.). Costs comprise two components. First, variable costs depend on the levels of service characteristics contained in the product offered. Marginal costs are a linearly increasing function of higher quality. Second, fixed costs are a function of static scale economies that depend on the size of current output. The learning task facing firms is to identify, through innovation, that combination of characteristics that are attractive to its target consumer type and maximise its target profit levels (i.e. for a given variable and fixed cost structure). The way in which firms' innovation is modelled differs significantly to the models previously discussed. First, firms are not satisfysing. They always seek to improve product performance if this can stimulate increased demand for their goods. Second, the search process is modelled using a 'learning algorithm' that is based on genetic algorithm.

The learning algorithm contains two operators, one that models imitation and one that models innovation. Imitation is modelled by a (uni-directional) 'selective transfer' operator ${ }^{7}$ that is implemented in the following way. Firms evaluate the changes made in their rivals' product offers - i.e. changes in product characteristics and prices - in the previous period, and changes in consumer demand for those products. A firm will imitate its rivals by introducing identical features - i.e. values of characteristics - if, ceteris paribus, it judges that this will improve its own performance. Innovation is the second operator of the learning algorithm, and is modelled as a stochastic process. In each period, a given number of characteristics (a parameter of the model) are randomly selected, and a new value for these characteristics is randomly generated. Importantly, both innovations and imitations are subject to an internal evaluation of their potential merit prior to their implementation. This involves a filtering process that is based on two criteria: technical issues (i.e. cost and design constraints), and the firm's understanding (i.e. current mental model) of the preferences of its target consumer class. These mental models are updated over time, in the light of previous experience.

The framework has been applied to two domains of technological competition. The focus of Windrum and Birchenhall (1998) is competition between rival, contemporaneous technologies leading to the emergence of distinct technological niches. The generic framework is tweaked in light of empirical observations on the

\footnotetext{
${ }^{7}$ This replaces the conventional (two-way) crossover operator of the standard genetic algorithm. While the crossover operator may be a useful approximation for sexual reproduction, with each parent exchanging parts of their genetic material to form offspring, it is clearly inappropriate to suggest that firms must engage in two way exchanges if one decides to imitate the other.
} 
product innovation phase of the product life cycle. In other words, the modellers use empirical observations to guide the formal modelling process. First, the operator controlling the generation of new consumer classes is switched off. Consequently, new consumer classes are not created to replace classes that are eliminated over the course of a simulation run. Stating with an initial number of consumer classes, competition will operate to reduce the number of classes until, in the limit, there remains one consumer class that is serviced by one or a handful of firms. This is 'dominant design' hypothesis that is tested in the paper. In order simplify the analysis, the number of firms is held constant throughout each simulation run. Hence, for every firm that exists the model, a new market entrant is created. Its initial product characteristics and costs structures, target consumer class, and mental model are randomly generated. The second tweak involves the dimensions of the characteristics space. Competition in the product life cycle is between rival variants of a common technology. Translating this into the characteristics framework, there is a set of services that is common to all competing variants. Where the rival variants differ is in the particular values of the services offered across these common dimensions (i.e. variants offer more or less of a particular service). Third, technological uncertainty regarding user tastes and technical possibilities is high in a new technology market and is common to all rival technology variants. For this reason, the strength of selection in the replicator algorithm is tempered slightly - i.e. a degree of noise (or 'fuzziness' as the authors call it) is introduced into the selection process.

The simulation model produces patterns of innovative activity that accord with those observed in the first phase of a product life cycle: the number of product innovations (imitations plus mutations in the model) initially rise and then continuously fall towards zero (at a diminishing rate) over time. Investigation of the outputs, however, indicates that this result does not depend on the emergence of a single 'dominant' design. It is also consistent with the emergence of multiple market niches, i.e. two or more consumer-firm couplings with products that have distinct characteristic sets. The paper goes on to conduct a sensitivity analysis of this result. Results are given for 80 simulation runs, each with different random seeds for class preferences, firms' mental models, initial designs and capacity. Attention is focused on the relationship between the number of firms operating in the market (the number of initial consumer types being held constant) and the number of stable consumer-firm couplings that emerge. The findings indicate a positive relationship between the number of firms operating in the industry and the probability of multiple niches emerging. This opens up once more the discussion of competition, and the individual and collective impacts of innovation. On the one hand, competitive pressure is higher the greater the number of competitors selling in the same niches market. One the other hand, however, the larger the pool of R\&D being conducted within a niche, the higher the probability of firms collectively identifying product variants that closely correspond to the preferences of their target consumer class, and hence the greater the probability that the niche will stabilise (i.e. continue to attract a sufficient number of consumers) over time. The authors note a number of empirical examples of industries that contain multiple stable niches over long periods of time.

In Windrum and Birchenhall (2001), the framework is applied to sequential technology competitions - specifically, the conditions under which new technologies 
offering improved performance quality can displace established technologies that enjoy large network externalities. Once again, the generic framework is modified to take into account empirical observations, this time on technological substitutions. The long run history of sectors such as transport and food indicate the emergence of new consumer classes with radically different preferences is a necessary condition for a technological succession, as is the conterminous entry of firms who seek to satisfy these new preferences through the introduction and development of new technology products. In this case, therefore, new consumer classes and new technology firms are introduced after old, poorly performing classes and firms are eliminated through selection. To simplify the analysis, the number of classes and firms are held constant throughout a simulation run. The elimination of an ineffective consumer-firm coupling therefore prompts the introduction of a new consumer-firm coupling.

Once again, the dimensions of the characteristics space need to be tweaked to the case at hand. The notion of distinct services offered by alternative technologies is formalised in the following way. New and old technology products differ in at least one dimension, i.e. a new technology product offers at least one service characteristic that is not offered by the old technology. In addition, the old and new technologies differ in the levels of services that are common to both technologies. However, it is the difference in characteristic dimensions that is the defining propriety of alternative technologies. Over long historical periods, a sequence of technological successions is associated with shifting dimensions of consumption, firms' competencies, and the characteristics of the technology products that are produced and consumed. Thus, for example, the evolutionary history of transport infrastructures has not simply been a transition from the horse to the car, or from public to private transport, but a long, drawn out process in which a sequence of co-evolutionary experiments with alternative modes of transport. Some, such as horse drawn trams and battery taxis no longer exist, while others, such as bicycles and trams, operate in certain niches or in certain countries.

The simulation model is capable of producing outputs that accord these patterns technology succession. The paper systematically tests the outputs for different random seeds and on random parameter values of four key variables that influence the quality-price relationship and, hence, may affect the probability of a succession occurring. Sensitivity analysis is reported on 400 simulations. The findings identify two key variables: the number of new dimensions offered by the new technology, and time. There is a positive relationship between the number of new dimensions offered by a new technology and the probability of a succession occurring. By contrast, there is a negative relationship between the time enjoyed by old technology firms to develop their designs and accrue network externalities, prior to the arrival of a new technology, and a succession occurring. Sensitivity analysis indicates that two of the variables tested do not consistently influence the probability of a succession occurring: incremental differences in the values of characteristics that are offered by both the new and old technologies, and differential rates of price reduction (due to different rates of unit cost reduction) between the new and old technologies. This suggests that consumers are relatively insensitive to marginal differences in prices or the quality of common characteristics, but will consider giving up the positive 
externalities associated with an established technology if the new technology offers a high degree of novelty.

The series of papers by Malerba, Nelson, Orsenigo and Winter mark an important contribution to simulation modelling - a contribution that will undoubtedly influence the future direction of simulation research within neo-Schumpeterian economics. Most attention has been placed on the methodological contribution of these papers. This will be examined in some detail. Yet very little attention has been paid to the issue of whether the models mark a significant break from the established neoSchumpeterian tradition. This issue is equally important and also needs to be addressed.

Malerba-Nelson-Orsenigo-Winter propose a solution to the problems that beset the first generation of simulation models (discussed in section 7): 'history-friendly modelling'. Much attention has been given to the methodological contribution of history-friendly modelling. Yet, on close inspection, we see that it represents an (incremental) development of the original Nelson-Winter two-step approach to the empirical validation rather than a radical break with the past. In essence, the historyfriendly method involves tying down simulation model to more carefully specified 'histories', i.e. to specific case studies for which a detailed empirical history exists. These detailed histories are used to inform the simulation work in a number of key respects. First, the modeller is to use empirical data as a guide when specifying the representations of agents (their behaviour, decision rules, and interactions) and the environment in which they operate. Second, detailed empirical case studies enable one to specify more demanding tests for the outputs of the model. Tests may, for example, involve comparing the model's outputs with data on market concentration, rates of innovation in different phases of the industry life cycle, rates of firm entry and exit, and distributions of firm size. Third, case studies can assist in the identification of particular parameters on key variables (from the many variables available in the model) that are likely to have been important in generating the observed history. Once a set of 'history-replicating parameters' are identified, the modeller can conduct sensitivity analysis to establish whether these lead to, in the authors' words, 'history divergent' results.

The Malerba-Nelson-Orsenigo-Winter approach is attractive in its elegance and coherence, and seems to offer clear guidance on a range of issues, including model specification and output testing. As we have seen, other researchers have in the past referred to particular historical cases when specifying their models and establishing appropriate tests for model outputs. Yet Malerba-Nelson-Orsenigo-Winter are the first to propose a historically grounded approach to simulation research. Given the significance of this new approach, and its likely influence on the future course of simulation modelling, we need to carefully evaluate its strengths and weaknesses. Let us therefore consider the authors' own application of the history-friendly approach.

To date, two history-friendly case studies have been developed, one on the evolution of the computer industry (Malerba, Nelson, Orsenigo and Winter, 1999; 2001, the 
other on the pharmaceutical/biotechnology industry (Malerba and Orsenigo, 2001). The former is the most widely known, so we shall take this as our illustration. Like Windrum-Birchenhall (2001), the authors develop a multi-agent model, containing consumers and firms, to investigate sequential technological competitions. In this model, however, quality is a simple integer value. This has a number of advantages, such as enabling the analysis to be conducted within a two-dimensional quality-price space. It has the disadvantage, however, of precluding the type of detailed analysis of quality differentiation dealt with by Windrum-Birchenhall. Prior to a simulation run, the two-dimensional quality-price space is divided by the modeller into a number of parts, of arbitrary size. Each part represents a different technology. By dividing the space into a series of compartments, a definite ordering of the space is introduced ${ }^{8}$. The compartment that contains the origin, for example, contains a set of designs that are lower in quality and higher in price than designs contained within the other compartments. In the computer industry model, the space is divided into two parts. The compartment containing designs with the lowest quality/highest price combinations is labelled 'the mainframe market' while the compartment containing designs with higher quality/lower price combinations is labelled 'the PC market'. The initial specification fundamentally determines the final outcome of the model. Depending on how the modeller specifies the boundaries of the two compartments in price/quality space, one or other 'market' will be the attractor state. Consequently, one no longer needs a replicator (or similar) algorithm to drive the selection process.

The two markets are further subdivided into a large number of independent niches, or 'sub-markets', by the modeller. Like Windrum-Birchenhall, a niche is defined as containing one consumer class. Since each class has a distinct preference set (here a particular point in quality/price space), the number of potential market niches is determined by the number of consumer classes that are initialised by the modeller. The utility functions of the classes are randomised within the overall quality/price parameters of each market segment (i.e. mainframe or PC), and remain fixed thereafter. Because user preferences are initialised as fixed points in quality/price space, a particular class will not become 'active' until a minimum level of quality/price performance has been reached. Once this threshold has been reached, the value that a consumer class places on a technology design becomes an increasing function of its performance and its cheapness. The utility of a design for a particular class is given by a Cobb-Douglas function in which the exponents are measures of the extent to the quality and price threshold requirements have been exceeded. Consumer utility also depends on the size of network externality associated with that design (measured by its current market share). In addition, utility depends on a third factor, advertising. It is assumed that the effect of advertising expenditures on sales follows a logistic curve. Together, brand loyalty and network externalities can lead to strong lock-in effects. There is, however, a clear ordering of the various components of consumers' utility sets in this model, with the strongest weight being placed on quality/price. Hence, lock-in effects become significant when one or more companies, with very similar quality/price designs, are trying to sell to the same consumer class.

\footnotetext{
${ }^{8}$ The exception would be if the space were divided by a number of arrays emanating from the origin.
} 
Firms' profits are gross margins on production costs, and are used in a number of ways. First, firms spend a constant fraction of their profits (set equal to $15 \%$ for all firms) to repay their initial debt with investors (which is the initial debt capitalised at a current interest rate). The reminder is then invested in R\&D and marketing activities. Firms are made up of sets of technological and marketing competencies, that are accumulated over time, and rules of action. These rules concern the research trajectories followed by firms, pricing decisions, $R \& D$ and marketing expenditure, the adoption of new technologies, and diversification into new markets. At the beginning of a simulation run, each firm is randomly initialised with an R\&D fund and a design (represented by a point in the two-dimensional quality-price space). Note that the first products are all mainframes - i.e. the modeller sets up the model so that the first set of products is located within the boundaries of the compartment containing the lowest quality/highest price combinations. Through innovation, the first set of firms search the pre-specified mainframe quality/price space, and succeed or fail in developing designs that satisfy a consumer class. Later, at a given time in a simulation run, a new group of firms are created and the design space is opened up to include the PC market. A new set of firms/designs is randomly distributed across the entire quality/price space, i.e. some will produce in the PC design space while others will produce in the mainframe design space. Once again, their survival depends on the identification of a design that satisfies the price/quality preference of a consumer class. If the initial endowment of a firm is exhausted before its design meets a consumer class' minimum quality-price threshold, then the firm goes bankrupt.

Firms use their R\&D budgets to finance innovation activities. In the model these are divided into equal amounts over a pre-specified number of periods. The returns to $\mathrm{R} \& \mathrm{D}$ depend on the research direction that each firm decides to follow, and on latent 'technological opportunities'. These opportunities are defined by the outer boundary of the mainframe and/or PC compartment in quality/price space. Hence, the closer a firm gets to its pre-specified boundary (measured in Cartesian distance), the lower the return for a given level of R\&D expenditure. Depending on how the boundaries of the price/quality space are set up in the model, the rates of returns to R\&D investment will differ. In the published implementation of the model, the size of the mainframe price/quality space is far smaller than that of the PC price/quality space. Hence, the returns to $R \& D$ in the PC market are far greater than those in the mainframe market.

$\mathrm{R} \& \mathrm{D}$ expenditures generate research competencies. In the model, $\mathrm{R} \& \mathrm{D}$ competencies take the form of two types of engineers: those that focus on reducing production costs (and hence price) and those that focus on improving computer performance (and hence quality). The joint action of these efforts determines the innovative path, or 'technological trajectory', that a firm pursues. This choice is highly path dependent and sensitive to initial experiences. For example, if a firm early on experiences increased profits as a consequence of quality improvements, then it will hire more staff to focus on further quality improvements. By contrast, if a firm benefits from improved price competitiveness, then it will increase the number of staff that focus on further cost reductions. Advertising expenditures similarly generate marketing competencies. These are, like R\&D expenditures, subject to depreciation, so firms who do not have the funds to invest will experience a deterioration of their competencies and the productivity of a given volume of expenditure fall. 
It is possible for old technology firms to switch to the new technology market. The incentive to switch is a function of the size of the PC market, defined in terms of sales, as compared to the mainframe market. Specifically, diversification becomes attractive when the ratio between the size of the PC market and the size of the mainframe market is bigger than a given threshold value (a parameter of the model). Again, we see that the initial specification of the boundaries of the quality/price space determines whether the mainframe or the PC market is the attractor state. The process of switching is not easy, and involves a number of steps. First, mainframe firms must recognise the need to switch. In the model, recognition is a function of the current technological position of the firm in relation to the technology frontier (i.e. the distance between the quality/price of its product and the outer boundary of the mainframe quality/price space), and of the progress realised by PC firms (measured as the distance between the outer boundary of the PC quality/price space and the quality/price position of the current best-practice PC firm).

Once a mainframe firm has perceived the need to switch, it must change its competence base. In the model, adoption costs comprise a fixed cost (that is equal for all firms), and the payment of a fraction of firms' accumulated budget to the creation of a new competence base. If firms' budgets are insufficient to cover these set-up costs, then they cannot switch markets. One advantage that successful old technology firms enjoy is their large profits, which can be used to diversity into the new technology. Diversification also occurs in a very specific way. As in KwasnickiKwasnicka (1992), it is assumed that firms diversify by setting up a spin-off company to produce the new technology product. Initially, the spin-off company inherits a fraction of its parent's budget, and R\&D and advertising capabilities (parameters of the model). The initial PC design is implemented by taking the current average quality PC design, and adding a degree of random noise. Once created, it is assumed the spin-off company acts independently, i.e. it has a separate budget, builds its own distinct set of R\&D, advertising and production competencies, and does not engage in cross-subsidies with its parent company.

The authors begin their output testing by observing the model is capable of generating outputs that mimic the stylised history of IBM. IBM came to dominate the old, transistor-based technology and continued to hold on to its large market share in mainframes when new, microprocessor technology firms entered the industry. The company continued to survive because it diversified into PCs and gained a significant (though not dominant) share of the new PC market. The authors then identify a set of key variables whose parameters determine whether 'history replicating' or 'history divergent' outputs are generated. Of the initial set of parameters that replicate the IBM story, attention is focused on two parameters in particular. Reporting on the findings of 50 simulation runs, the authors observe that the 'history replicating' pattern requires a relatively high coefficient on market share in consumer demand for mainframes, and a lower coefficient in consumer demand for PCs. The values of these coefficients represent network externalities and branding effects, suggesting 
consumer lock-in was greater in the mainframe market than the PC market ${ }^{9}$. Reducing the parameter coefficient in mainframe demand lowers market concentration. At some point, as the parameter is lowered, a dominant firm (with resources sufficient to later establish a new spin-off PC company) will no longer emerge. This is the point at which the model starts to generate 'history divergent' outputs. The second parameter investigated is the timing of the new technology. Given that it takes a certain time (i.e. iterations of the simulation model) for a dominant firm to build up the resources necessary to establish a spin-off company, replication of the IBM pattern means the new technology cannot introduced too quickly. The timing of the new technology is thus a critical parameter.

Having discussed the model in some detail, we are now in a position to evaluate this implementation of the history-friendly method. Let's address two questions. First, to what extent are the modelling choices and test procedures determined by the history of the computer industry? Second, to what extent can we actually rely on history to be the final arbiter? The first question is concerned with application, the second with methodology. With regards to the first question, it is noticeable that many of the distinguishing features of the model do not follow from the stylised history presented in the paper but from the two-dimensional design space in to which consumer references and firms' designs are placed. This is the reason why consumer utility functions have quality and price thresholds, and why there is a distinct ordering within these utility functions between, on the one hand, quality/price and, on the other, network externalities and branding. Further, it is this particular framework, not history, which precludes a detailed investigation of how quality differentiation affects the dynamics of sequential technological competitions. The Windrum-Birchenhall paper illustrates that such an investigation is possible in an alternative framework.

In a similar vein, the specification of $R \& D$ competences, and the process by which old technology firms diversify into the new technology market are not based on the history of the computer industry. Rather, as the authors themselves state, they have been influenced by the theoretical literature on dynamic competencies. There are many alternative ways for firms to switch markets without the need to set up a spinoff company and, indeed, IBM did not do thus when it entered the PC market. Clearly, a number of other factors besides the specific history have influenced the modelling choices made at various points. It would seem, then, that modelling choices invariably extend beyond a historical case study. There are those who would argue that a historically-grounded method requires the modeller to give precedence to the historical evidence above all other considerations. But what are we to do if the evidence is incomplete, offers no guidance on a particular point, or else seems to contain alternative, competing viewpoints? This is a complicated discussion that cannot be addressed in the limited space here. However, good practice suggests that modellers follow Malerba-Nelson-Orsenigo-Winter in being as open as possible when choices are based on factors other than the particular history at hand.

\footnotetext{
${ }^{9}$ The authors do not provide empirical data on the relative sizes of network externalities and branding in the mainframe and PC markets, and so we cannot assess whether this was actually the case.
} 
The discussion of modelling choices brings us to an issue that has thus far received little attention but which is of great importance. Modelling decisions are taken within a context - in this case it is a tradition established by the first generation of modellers, of which the two founding fathers are co-authors of this framework. Within this context, certain modelling decisions are particularly significant. In particular, the move away from modelling innovation as an open-ended search process, and the use of a selection algorithm. Analysing sequential technological competitions within a two-dimensional design space has many attractions. The resulting model is elegant and simple to comprehend. Further, setting up an attractor state within this space means one no longer needs to use a selection algorithm. By setting up the boundaries of the quality/price space in a certain way, the end point of the simulation is hardwired from the outset. In this model, innovation is not an open-ended search process. As we have seen, open-ended search algorithms and selection algorithms are the distinguishing features of (Type 2) neo-Schumpeterian models. Jettisoning these algorithms therefore represents a radical break from the established tradition. So much so, that it raises the question of whether models such as this can be described as neo-Schumpeterian. Clearly, the question has far reaching implications for the future course of neo-Schumpeterian modelling.

Let us next turn to the issue that has attracted attention: the methodology of historyfriendly modelling. To what extent can case histories guide the testing of model outputs? The history-friendly method suggests the answer is clear-cut but, in practice, things are far from simple. For instance, implementing history replicating and history divergent simulations requires a 'typical' history. Yet a typical history, i.e. an invariant history that is common for all firms, does not exist. Hence, one must resort to some form of 'stylised' description of events. This may be a stylised description of the industry in general, or else a stylised description of a particular firm. The choice is arbitrary. Malerba-Nelson-Orsenigo-Winter chose the latter, presenting a stylised account of IBM's past. Equally, they could have chosen Microsoft, Sun, Netscape or Hewlett Packard. However, the stylised accounts provided by these companies would be very different to that provided by IBM. Since the test procedures are highly sensitive to the particular account that is (arbitrarily) chosen, the terms of reference for 'history replicating' and 'history divergent' runs will change, as will the set of variables that are identified for sensitivity analysis. There appears to be no way out of this conundrum.

This leads us to a fundamental question. To what extent can we actually rely on history to be a final arbiter? To pose the question in another way, can simulations, in principle, be guided by history? In practice, it is unlikely that we will be able to appeal to history, either to bear witness, or to act as a final arbiter in a dispute. This is because history itself is neither simple nor uncontested, and any attempt to develop a historically grounded approach to modelling faces deep level methodological problems. At one level, the contestability of history is evidenced by the ongoing debate about whether inferior quality variants can win standards battles. Leibowitz and Margolis (1990) have contested the suggestion that the QWERTY keyboard (David, 1985) and the DOS operating system (Arthur, 1988) were inferior quality variants, bringing forward data that suggests they were, in fact, superior in quality. 
But the contestability of history exists at a second, far more significant level. E.H. Carr, in his classic work 'What is History?', observed that history is not simply a collection of 'facts' whose meaning is recognised and agreed on by historians. The writing of history is itself a creative process in which many pieces of 'data', bequeathed to us from the past, are filtered by the historian. The historian gives prominence to some of these pieces of data. These are accorded the status of 'historical fact'. A historian presents in his/her account of the past, a narrative that communicates to the reader the significance, and the relationship between, the set of 'facts' that have been selected. There are a number of issues here. To begin with, the data that the one begins with is itself pre-selected. Some records have been fortuitously bequeathed by the past (i.e. not destroyed) but many will be missing. Of those that exist, these will have been recorded for a particular purpose and in a particular way. This will not be impartial. For example, they may be the subjective viewpoints expressed by people who could write, and who chose to record them. Equally, statistical datasets were (as now) construction according to criteria that reflect certain choices and, as a consequence, have inbuilt biases. As econometricians know only too well, data that may subsequently assist in a particular discussion will simply not have been collected. Such problems exist with data from the recent past, just as it does for data from the more distant past.

In addition to the partialness of the initial data, Carr noted how we are keenly aware of the contestability of current events, and the construction of alternative interpretations of those events. Witness, for example, the recent divisions in the United Nations and across the world over whether to engage in the war against Iraq. The same was true for events in the past. One cannot, therefore, appeal to history for a single set of incontrovertible and uncontested 'facts'. In the end, one can only provide an 'account' of history - an account that will be partial and contestable. Does acknowledging the process of writing history, and its inherent limitations, automatically imply the adoption of a post-modernist position of subjective relativism? Can we not distinguish between good or bad history writing? Is any viewpoint, however ludicrous, is justifiable? Certainly not. The logic of Carr's reasoning leads to a call for detailed, high quality historical studies. These should present, as best possible, the data that is currently known, highlighting contradictions between alternative sources and disputes over their interpretation. In this way, each account openly acknowledges its own limitations. Further, an account cannot be complete but is part of an unfolding sequence of writing on the subject.

The development of high quality accounts, open to critical scrutiny, is essential to the history-friendly approach, or indeed for any other historically grounded methodology. It is, after all, on the basis of these accounts that guidance is taken on particular modelling choices, the critical evaluation of outputs, and sensitivity analysis. In recognising the limitations of any historical account, we simultaneously recognise the limitations of decisions that are based on that account. But this is a strength, not a weakness, of open academic discourse. How, then, are we to proceed? Let me suggest the following possibility. While a single 'typical' history may not exist, we may be able to draw some generalisations on the basis of a large collection of historical case studies. This is not unlike the situation in pre-Darwinian biology. For 
many centuries botanists spent their time identifying and categorising different species without an underpinning theory of evolution. Yet their work was an essential prerequisite for Darwin formulating his theory of speciation. So far, there are only a few examples of historically-grounded simulation models but there is a wealth of empirical studies within the neo-Schumpeterian tradition, written over the last twenty years, that can be drawn upon. Importantly, modellers embarking on this project would need to ensure that they do not to prematurely constrict their models. If the models are not flexible enough to consider alterative scenarios, then we will be left with a set of models that are more, not less, incompatible with one another.

In summary, the pursuit of a historically grounded modelling methodology seems to offers significant promise. Yet, the history-friendly method - or any attempt at a historically grounded approach - is not without its problems. Reasonable expectations also need to set. Recourse to history cannot guarantee solutions to all of our modelling problems. It will not necessarily help us identify the dynamics that give rise to a set of unconditional objects, or tell us how to correctly model the behaviour of agents, their learning routines, rules of interaction, and so on. In part, the benefits that are to be gained from a history-friendly approach will depend on the quality of the historical accounts that are developed. In part, the benefits will reflect the modeller's ability to recognise, and handle, the limitations of the method, the quality of the modelling choices that are made on the basis of the available, and (as ever) the quality of the models themselves.

\section{Conclusions}

The paper has traced the evolution of neo-Schumpeterian simulation modelling, from the Nelson and Winter growth model and the first generation of models that it inspired, through to recent contributions. One is struck by the rapid development that has occurred. There has been a consistent reappraisal of the boundaries of research, both with respect to the range of phenomena studied and the content of the models. Today, modellers are investigating issues that were once considered beyond the remit of neo-Schumpeterian economics. What is more, they are developing sophisticated multi-agent and other frameworks that were simply unimaginable when Nelson and Winter first began to experiment with simulation.

There has certainly been evolution. But there has also been a development of distinctive features that set neo-Schumpeterian models apart from other models, and which gives them a collective coherence. This coherence exists at two levels. First, there is a clear view about the type of world in which real economic agents operate. Second, there is an identifiable set of algorithms that make up a neo-Schumpeterian simulation model. According to neo-Schumpeterians, real economic agents exist in a world that is inherently unpredictable. They cannot know the outcomes of a particular choice or course of action ex ante. This is the basic starting premise of all neoSchumpeterian models. 
Five significant aspects of this world were identified. First, agents engage in innovation, defined as the open-ended search for novelty. This can involve a search for new product designs, new techniques of production, new competencies, new tastes etc. Second, search is conducted within dynamically changing environments. Since agents cannot know or predict the outcomes of their actions, they must adapt and learn about the underlying structure of the environment in which they operate. This is complicated by the fact that agents' actions impact on, and change, their environment. Third, interactions between agents are non-linear. Small initial differences in a population of heterogeneous agents are magnified over time, leading to emergence of very different macro phenomena. Fourth, economic systems contain selection mechanisms that operate on variety. Novelty generated by innovative search is retained provided it is suited to its environment. Finally, the interaction of variety and selection drives the economic system far-from-equilibrium. The aggregate regularities that appear are not equilibrium properties but emergent properties that arise through this interaction

In terms of code, the paper identified three key elements in all neo-Schumpeterian simulation models: a search algorithm, a selection algorithm, and a population of objects in which variation is expressed and on which selection operates. Since Nelson and Winter's growth model, the search algorithm has contained two components, one behavioural and one stochastic, in order to capture the complex nature of innovation. On the one hand, agents' search their environment in a structured way, i.e. there are identifiable behaviours, organisational rules and responses. On the other hand, innovation has a stochastic component. Not only can purely random, serendipitous discoveries occur, but also the payoffs for truly radical innovations (i.e. those that are unlike anything previously introduced) cannot be predicted ex ante. Indeed, a common distinction is often made between gradual and radical innovation. Behavioural search is typically associated with incremental innovation, associated with a gradual improvement in the performance of existing objects, often drawing upon the experiences of other agents as well as one's own. By contrast, radical innovation involves the blind search of the unknown. Lessons cannot be learnt from the past or from the experience of others.

Much attention has been paid to selection algorithms, and the replicator in particular. Together, open-ended search and selection algorithms form the dynamic cornerstone of neo-Schumpeterian simulation models, and the diligence of the first generation of simulation modellers in developing these algorithms cannot be underestimated. The third block of simulation code defines the population of objects (product designs, production techniques, competencies, tastes etc.) in which the variation generated by innovative search is expressed, and on which selection operates. This block of code also typically includes rules regarding the introduction of new objects (e.g. the arrival of new vintages of technology) and agents (e.g. new market entrants) into the system.

It was against this background that more recent modelling contributions can be considered. Two in particular were discussed in this paper, the Windrum-Birchenhall framework, and the Malerba-Nelson-Orsenigo-Winter framework. As is common for 
second generation models, they seek to address new research questions and introduce novel modelling techniques. Windrum-Birchenhall is a multi-agent framework that contains a modified GA to model the innovation process. A replicator is used but this operates on the interactions between agents, e.g. of consumer-firm couplings. Yet, the Windrum-Birchenhall framework clearly remains within the established neoSchumpeterian tradition. By contrast, the Malerba-Nelson-Orsenigo-Winter framework marks a significant break from that tradition because it jettisons both selection algorithms and open-ended search algorithms. Interestingly, the historyfriendly method, which has initially attracted much more attention, does not represent so much a radical break with the practices of earlier (or contemporary) modellers but is an extension of Nelson and Winter's original method.

It is perhaps indicative of the vitality of the neo-Schumpeterian research community that Nelson and Winter, the founding fathers of neo-Schumpeterian simulation, should themselves continue to pose fundamental questions regarding methods and content. Much has been achieved over two decades, yet there is still much work to be done. For example, little or no simulation work has been conducted on the role government and other public sector agents in the innovation process, while work has only recently begun on issues of supply chains, innovation networks, services innovation, and economic geography. As these areas are addressed by the vibrant research community, the boundaries of the neo-Schumpeterian research agenda will no doubt continue to evolve, stimulating further debates about methods and content and, perhaps, even necessitate a redefinition of what constitutes a 'neo-Schumpeterian' simulation model. 


\section{Bibliography}

Arthur, W.B., 1988, 'Competing Technologies: An Overview.' In G. Dosi, C. Freeman, R. Nelson, G. Silverberg and L. Soete (eds.), Technical Change and Economic Theory, London: Pinter, 590-607.

Arthur, W.B., Ermoliev, Y. M. and Kaniovski, Y.M., 1987, Path Dependent Processes and the Emergence of Macrostructure, European Journal of Operational Research, 30, 294-303.

Banerjee, A., 1992, A simple model of herd behaviour, Quarterly Journal of Economics, 108, 797-817.

Brock, W.A. 1999, Scaling in economics: a reader's guide, Industrial and Corporate Change, 8 (3), 409-446.

Bruckner, E., Ebeling, W., Jiménez-Mantaño, M.A., and Scharnhorst A., 1994, Hypreselection and innovation described by a stochastic model of technological evolution, in L. Leydesdorf, and P. van den Besselaar (eds.), Evolutionary Economics and Chaos Theory, London: Pinter.

Carr, E.H., 1961, What is History?, London: Macmillan.

Chiaromonte, F. and Dosi, G., 1993, Heterogeneity, competition, and macroeconomic dynamics, Structural Change and Economic Dynamics, 4, 39-63.

David, P.A., 1985, 'Clio and the Economics of QWERTY', American Economic Review, 75, 332-336.

David P.A., 1997, Some new standards for the economics of standardisation in the information age. in The Economic Theory of Technology Policy, P. Dasgupta and P.L. Stoneman (eds.), Cambridge: Cambridge University Press, 206-239.

Dosi, G., Fabiani, S., Aversi, R., and Meacci, M., 1994, The dynamics of international differentiation: a multi-country evolutionary model, Industrial and Corporate Change, 2(3), 225-241.

Dosi, G., Marsili, O., Orsenigo, L., and Salvatore, R., 1995, Learning, market selection, and the evolution of industrial structures, Small Business Economics, 7, 411-436.

Fisher, R.A., 1930, The Genetical Theory of Natural Selection, Oxford: Clarendon Press.

Fundenberg, D. and Levine, D.K., 1998, Theory of Learning in Games, Cambridge, Mass.: MIT Press.

Goldberg, D.E., 1991, Genetic Algorithms, Reading: MA., Addison-Wesley. 
Gribbin, J., 1984, In Search of Schrödinger’s Cat, London: Black Swan.

Hofbauer, J. and Sigmund, K., 1998, Evolutionary Games and Population Dynamics, Cambridge: Cambridge University Press.

Holland, J.H., Holyoak, J.K., and Thagard., P.R., 1989, Induction of Inference, Learning and Discovery, Cambridge, MA.: MIT Press.

Kirman, A., 1991, Epidemics of opinion and speculative bubbles in financial markets, in M. Taylor (ed.) in Money and Financial Markets, London: Macmillan.

Knight, F.H., 1921, Risk, Uncertainty, and Profits, Chicago: Chicago University Press.

Kuhn, T.S., 1962, The Structure of Scientific Revolutions, University of Chicago: Chicago.

Kwasnicki, W., 2001, Comparative analysis of selected neo-Schumpeterian models of industrial dynamics, Conference in Honour of Richard Nelson and Sydney Winter, Aalborg, $12^{\text {th }}-15^{\text {th }}$ June 2001

Kwasnicki, W., and Kwasnicka H., 1992, Market, innovation and competition, Journal of Economic Behaviour and Organisation, 19, 343-368.

Lancaster, K., 1971, Consumer Demand: A New Approach, Columbia: Columbia University Press.

Leibowitz, S. J. and Margolis, S.E., 1990, 'Fable of the Keys', Journal of Law and Economics, 33, 1-25.

van Lente, H., 1993, Promising Technology: The Dynamics of Expectations in Technological Developments, PhD Dissertation, University of Twente, The Netherlands.

MacKenzie, 1992; Economic and sociological explanations of technological change, in R. Coombs, P. Saviotti, and V. Walsh (eds.), Technological Change and Company Strategies: Economic and Sociological Perspectives, London: Academic Press.

Malerba, F., Nelson, R.R., Orsenigo, L., and Winter, S.G., 1999, History friendly models of industry evolution: the computer industry, Industrial and Corporate Change, 8(1), 3-41.

Malerba, F., Nelson, R.R., Orsenigo, L., and Winter, S.G., 2001, Competition and industrial policies in a 'history friendly' model of the evolution of the computer industry, International Journal of Industrial Organization, 19, 613-634.

Malerba, F., and Orsenigo, L., 2001, Innovation and market structure in the dynamics of the pharmaceutical industry and biotechnology: towards a history friendly model, Conference in Honour of Richard Nelson and Sydney Winter, Aalborg, $12^{\text {th }}-15^{\text {th }}$ June 2001, 
Metcalfe, J.S., 1988, The diffusion of innovations: an interpretative survey, in G. Dosi, C. Freeman, R. Nelson, G. Silverberg, and L. Soete (eds), Technical change and Economic Theory, London: Pinter.

Nelson R.R., and Winter, S.G., 1982, An Evolutionary Theory of Economic Change, Cambridge, Mass.: Harvard University Press.

Samuelson, L., 1997, Evolutionary Games and Equilibrium, Cambridge, Mass.: MIT Press.

Silverberg, G., 1987, Technical progress, capital accumulation and effective demand: a self-organisation model, in Economic Evolution and Structural Adjustment, D. Batten, J. Casti and B. Johansson (eds.), Berlin, Heidelberg, New York: SpringerVerlag.

Silverberg, G., Dosi, G., and Orsenigo, L, 1988, Innovation, diversity and diffusion: a self-organisation model, Economic Journal, 98, 1032-1054.

Silverberg, G., and Lehnert, D., 1993, Long waves and evolutionary chaos in a simple schumpeterian model of embodies technical change, Structiral Change and Economic Dynamics, 4, 9-47.

Silverberg, G., and Verspagen, B., 1994, Learning, innovation and economic growth: a long-run model of industrial dynamics, Industrial and Corporate Change, 3:1, 199223.

Silverberg, G., and Verspagen, B., 1995, Evolutionary theorizing on economic growth. A survey, Merit Research Memoranda 2/95-017, Maastricht, NL: Merit, subsequently published in The Evolutionary Principles of Economics, K. Dopfer (ed.), Norwell, MA: Kluwer.

Soete, L. and Turner, R., 1984, Technological diffusion and the rate of technical change, Economic Journal, 94, 612-623.

Solow, R., 1957, Technical change and the aggregate production function, Review of Economic Statistics, 29, 312-320.

Verspagen, B., 1993, Uneven Growth between Interdependent Economies. The Evolutionary Dynamics of Growth and Technology. Aldershot: Avebury.

Verspagen, B., 1995, Convergence in the world economy: a broad historical overview, Structural Change and Economic Dynamics, 6, 143-166.

Weibull, J., 1995, Evolutionary Games Theory, Cambridge, Mass.: MIT Press.

Weisbuch, G., Kirman, A. and Herreiner, D., 2000, Market organisation and trading relationships, The Economic Journal, 110, 411-436. 
Windrum, P., 1999, Simulation models of technological innovation, American Behavioral Scientist, 42, 1531-1550.

Windrum, P., and Birchenhall, C., 1998, Is life cycle theory a special case?: dominant designs and the emergence of market niches through co-evolutionary learning, Structural Change and Economic Dynamics, 9, 109-134.

Windrum, P., and Birchenhall, C., 'Modelling technological successions in the presence of network externalities', Conference in Honour of Richard Nelson and Sydney Winter, Aalborg, $12^{\text {th }}-15^{\text {th }}$ June 2001, forthcoming in Journal of Evolutionary Economics as 'Technological diffusion, welfare and growth: technological succession in the presence of network externalities'.

Winter, S.G., Kaniovski, Y.M., and Dosi, G., 2000, Modelling industrial dynamics with innovative entrants, Structural Change and Economic Dynamics, 11, 255-293.

Yilizoglu, M., 2001, Competing R\&D strategies in an evolutionary industry model, Computational Economics, 19, 51-65. 